\title{
A low-tech approach
}

\section{Working with persons with mobility and speech disabilities in an academic library}

by Denise A. Forro

$\mathrm{T}$ oday, we rely more heavily than ever before on technology to handle various library challenges, and rightly so. Technology has allowed us to process materials and serve our patrons with a series of keystrokes. However, there are some situations that can be readily handled by non-tech or low-tech solutions.

Several years ago, the information desk staff at Michigan State University Libraries expressed concern about answering the questions of a person with mobility and speech impairments. The patron was unable to articulate his questions and was unable to write his questions due to the limited use of his hands. Desk staff were concerned that the interactions were frustrating, time-consuming, and ultimately ineffective in serving the needs of the patron. Clearly, something needed to be done to improve this situation. While it was agreed that technology might offer some sort of resolution, a non-tech approach was sought.

To investigate alternative solutions, we turned to a university staff member who exhibited the same physical attributes as the library patron. This person was a member of a special committee on campus, the Accommodating Technology Committee. Although he used a computer in his office with voice output, he did not have access to that computer when traveling to various units across campus.

\section{A low-tech solution}

In the meetings, the staff member would interact quite effectively with the other members of the committee through the use of a word board, also known as a communication board. After studying the use of this device, it became apparent that this tool might be useful in the interactions with our various patrons who had similar physical and verbal impairments.

Literature searches and a search of Internet resources were performed to discover if other libraries were using this type of low-tech device. While the searches did not produce useful results, it was discovered through our library catalog that we owned a source that could be used to develop a word board.' This title outlined the methods for determining the use of the board and what words should be represented. It also gave many excellent examples of word boards that had been developed.

Word processing software was used in our initial efforts to develop a word board, but we quickly discovered that such software was not designed for creating the kind of layout needed for the board. The original text of the word board was forwarded to the library's graphics person. An outline of the purpose of the board and a list of words, phrases, and numbers were given to our graphics designer and, after much

\section{About the author}

Denise A. Forro is coordinator of assistive technology services at Michigan State University Libraries, e-mail: forro@mail.lib.msu.edu 


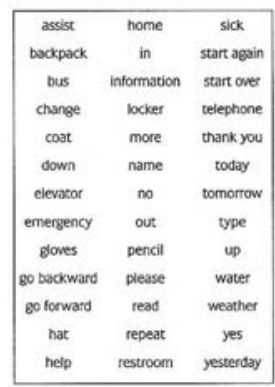

Figure 1.

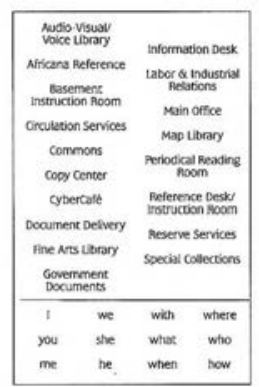

Figure 2 .

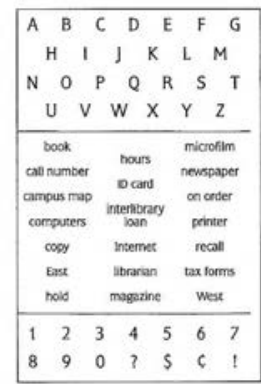

Figure 3. discussion, a board was developed using PageMaker software. PageMaker made it easy to manipulate the information and place it in the appropriate areas.

\section{Getting approval}

When the mock-up copy of the word board was completed, the information desk staff re viewed it and made comments and suggestions. Following this process, the word board mockup was taken to other units to be presented at meetings and reactions were solicited. Finally, appropriate changes were made and additions were added to the original product.

As a final step in the solicitation of responses, the staff person from the Accommodating Technology Committee reviewed the board. He carefully scrutinized the product and tested it thoroughly. After a very intense conversation using the library word board, he enthusiastically approved the board and applauded the efforts of the library.

In developing the board, many things were taken into consideration. In order to make the word board useful to someone lacking manual dexterity, the size of the words needed to be large and the white space sufficient for accurate use. Therefore the size of the board itself was an important consideration. It was determined that a ledgersized tri-fold would be easy to reproduce in-house. The size was also considered to be manageable for both staff and patrons.

The words used on the word board were selected because of their relevance to the $1 \mathrm{i}$ brary and the needs of patrons in the library (Figure 1). In addition, the most common Main Library locations were also represented as a list (Figure 2). As with most communication boards, an alphabet and numbers were also included in the final product (Figure 3 ).

With the assistance of the libraries' preservation staff, the pages were placed on a heavy card stock and laminated; hinges were made to join the three leaves together. A map of the campus was attached to one outside leaf, while a mock white board for writing messages was affixed to the other blank surface (Figure 4).

To communicate with pa-

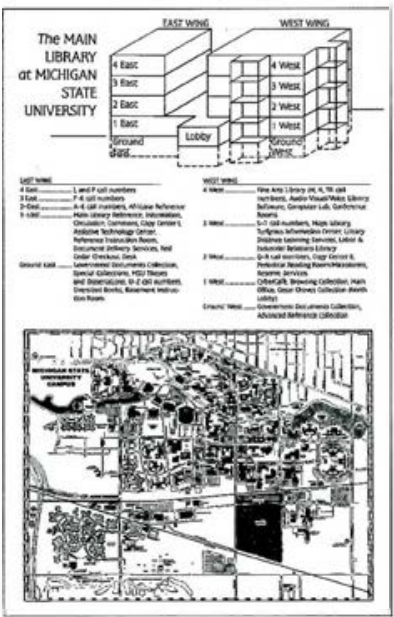

Figure 4. trons who exhibit mobility and speech disabilities, the staff person lays the board out on a surface and invites the patron to signal by hand motions the words or letters that depict what he or she wants to communicate. If the patron is unable to gesture to the appropriate words or letters, the staff person points to the various symbols until the patron indicates that the selection is appropriate. Staff are then able to respond and direct the patron as necessary. This proves to be an effective communication tool and resource for staff.

Multiple copies of the word board have been created 
and distributed. Although not heavily used, when the board is employed both the patron and the staff involved agree that it facilitates communication efforts and contributes to successful interactions.

While technology has been a boon to persons with disabilities, after working with this project and determining its effectiveness in serving patrons with mobility and speech impair- ments, it is apparent that a low-tech approach has definite benefits.

\section{Note}

1. United Cerebral Palsy Associations of New York State. Rochester-LeRoy Area Study Group. Apbonic Communication For Those With Cerebral Palsy. New York: United Cerebral Palsy Associations of New York State, 1967.

\section{Letters to the editor}

Editor's note: We received several letters in response to "Retbinking library development: the ethical implications of library fundraising, "by Pbillip J. Jones, which ran in the "The Way I See It" column in September. The following are excerpts from some of these responses.

Mr. Jones expresses a concern that collection growth may be dictated by the donor, not the librarian. This concern can easily be overcome by developing guidelines in advance and then sharing those guidelines with prospective donors. I have found that donors interested in donating their collections, or portions thereof, understand the need to focus collections. According to the Donor Bill of Rights, donors have the right to be informed of the organization's mission, of the way the organization intends to use donated resources, and of its capacity to use donations effectively for their intended purposes. I would encourage $\mathrm{Mr}$. Jones and other librarians to review this document as well as the "Code of Ethical Principles and Standards of Professional Practice." These can be found on the Web site of the Association of Fundraising Professionals (AFP). Every fundraiser who is a member of AFP adheres to these standards. - Caroline J. Punches, San Jose State University, cpunches@sjsu.edu

As a library development officer, I object to Mr. Jones's characterization of library development as the corruptor of librarians" ethics. Every library development officer I've met has worked very hard to build strong collegial relationships with library faculty, and an article like this one, published without any counterpoint, can do real damage to those relationships. Also, development professionals work even harder to create relationships with prospective and current donors that will allow us, when the right time comes, to match the donors' needs (e.g., for recognition, to "give something back") to the library resource needs of our students and faculty.-Tina Surman, University of Miami, tsurnan@niamiedu

Are librarians and fundraisers incompatible bedfellows? No doubt the quest for money can undermine a library. It can equally mislead a school, a church, a hospital, the United Way, the Red Cross, families, and individuals. Libraries are no more and no less susceptible to the seduction of money. Choosing to ignore fundraising may provide libraries with an escape from temptation, but noble budget shortfalls will hobble their attempts to implement their missions.

The choices are not really that stark. I believe that discourse about mission and ethics provides a secure, high ground. Just like a librarian, a fundraiser must know what her organization's mission is. Librarians have the advantage over fundraisers of internalizing their discourse in the process of studying librarianship. Fundraisers need to receive explicit communication about the nature of their particular library's mission . . . Development professionals know that mission drives fund raising and that ethics are its bedrock. Without these two things institutional advancement is by definition unprofessional and in reality unsuccessful. By valuing both, librarians and fundraisers share essential habits of thought. -Dale Walker, University of Cbicago, dualker1@miduxt.uchicago.edu. 